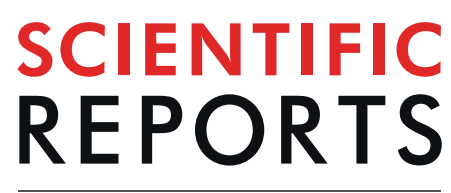

natureresearch

\title{
No Evidence of Off-label Use of Olodaterol and Indacaterol in Denmark, France, and the Netherlands: A Drug Utilization Study
}

\author{
Cristina Rebordosa $\mathbb{D}^{1,2^{*}}$, Eline Houben $\mathbb{1}^{3}$, Kristina Laugesen $\mathbb{D}^{4}$, Ulrich Bothner $\mathbb{D}^{6}$, \\ Jukka Montonen $\mathbb{D}^{6}$, Jaume Aguado $\mathbb{B}^{1,2}$, Jetty A. Overbeek $\mathbb{D}^{2}$, Vera Ehrenstein $\mathbb{D}^{4}$, \\ Joelle Asmar ${ }^{5}$, Laura Wallace $\mathbb{B}^{7}$ \& Alicia W. Gilsenan $\mathbb{1}^{1,2}$
}

To characterize the use of olodaterol and indacaterol in clinical practice and to quantify the off-label use in asthma. Drug utilization study of new users of olodaterol or indacaterol between 2014 and 2017 in the PHARMO Database Network in the Netherlands, the Danish population registers, and the IMS Real-World Evidence Longitudinal Patient Database panels in France. On-label use was defined as use among adults with a recorded diagnosis of COPD. Off-label use was defined as use among adults with a recorded diagnosis of asthma without a recorded diagnosis of COPD or as use among patients aged $\leq 18$ years. Potential off-label use was defined as no recorded diagnosis of either COPD or asthma. The study included 4,158 new users of olodaterol and 9,966 new users of indacaterol. Prevalence of off-label use ranged from $3.5 \%$ for both drugs to $12.4 \%$ for olodaterol and $11.9 \%$ for indacaterol. Prevalence of on-label use ranged from $47.8 \%$ to $77.7 \%$ for olodaterol and from $28.7 \%$ to $70.1 \%$ for indacaterol. The remaining new users of olodaterol and indacaterol were classified as potential off-label users, with prevalence ranging from $17.3 \%$ to $48.6 \%$ for olodaterol and from $20.5 \%$ to $66.6 \%$ for indacaterol. This study provides no evidence of a major concern in Europe for olodaterol or indacaterol for off-label use in asthma or for pediatric use.

Chronic obstructive pulmonary disease (COPD) affects 174 million people worldwide ${ }^{1}$. It is a characterized by persistent airflow limitation that is due to airway and/or alveolar abnormalities usually caused by significant exposure to noxious particles or gases including smoking ${ }^{2}$. Four inhaled long-acting beta2-agonists (LABAs) (salmeterol, formoterol, indacaterol, and olodaterol) are approved for long-term maintenance treatment in patients with COPD. Salmeterol and formoterol are also approved for use in asthma. Olodaterol was first approved in the countries of the European Union since 2013 and is indicated as a maintenance bronchodilator treatment to relieve symptoms in adult patients with $\mathrm{COPD}^{3}$. The use of LABAs as monotherapy in asthma without COPD, without a primary anti-inflammatory controller medication, e.g., an inhaled glucocorticosteroid (ICS), has been associated with increased morbidity and mortality ${ }^{4,5}$. There were no such concerns if the patient has COPD and concomitant asthma, an overlap of asthma and COPD, or COPD alone. Therefore, the health authorities of the European Union (EU)/European Economic Area Member States requested the conduct of a post-approval drug utilization study to characterize the use of olodaterol in clinical practice and assess the potential off-label use of olodaterol in asthma (see study protocol at EU PAS Register \# EUPAS 17386) ${ }^{6}$. The main objectives of the study were to describe the baseline characteristics of patients initiating on olodaterol and to quantify off-label use of

${ }^{1}$ RTI Health Solutions, Av. Diagonal 605, 9-1, 08028, Barcelona, Spain. ${ }^{2}$ Research Triangle Park, NC, North Carolina, USA. ${ }^{3}$ PHARMO Institute for Drug Outcomes Research, Van Deventerlaan 30-40 3528 AE, Utrecht, Netherlands. ${ }^{4}$ Department of Clinical Epidemiology, Aarhus University Hospital, Olof Palmes Allé 43-45, 8200, Aarhus N, Denmark. ${ }^{5}$ IOVIA, RWI, Tour D2, 17 Bis Place des Reflets, TSA 64567, 92099, La Défense Cedex, France. ${ }^{6}$ Boehringer Ingelheim International $\mathrm{GmbH}$, Binger Str. 173, 55216, Ingelheim am Rhein, Germany. ${ }^{7}$ Boehringer Ingelheim International GmbH, 900 Ridgebury Road, Ridgefield, CT, 06877, USA. *email: crebordosa@rti.org 
olodaterol to treat asthma in three countries in Europe. To provide a meanin gful context for the results, we also describe characteristics and off-label use of indacaterol, the other LABA not indicated to treat asthma.

\section{Methods}

Study design. We conducted a multinational, cross-sectional drug utilization study using information routinely collected in health care databases of new users of olodaterol or indacaterol. The study was conducted using health care databases in three countries: the PHARMO Database Network in the Netherlands (PHARMO overall and PHARMO General Practitioner [GP]) (www.pharmo.com) ${ }^{7}$, the Danish population registers in Denmark ${ }^{8-11}$, and the IMS Health Information Solutions Real-World Evidence Longi tudinal Patient Database (IMS RWE LPD) (GP panel and pulmonologist panel) in France ${ }^{12}$. Characteristics of the health care databases are described in Supplemental Table 1. Briefly, PHARMO overall includes electronic medical records (EMRs), of hospitalizations and outpatient pharmacy dispensings for more than 4 million residents of a well-defined population in the Netherlands (approximately 25\% of that country's population) for an average of 10 years. The PHARMO-GP is a 25\% subset of the PHARMO overall that also includes EMRs from GPs. The Danish population registers used in this study were the Danish National Patient Register ${ }^{9}$, an administrative registry tracking hospitalizations and outpatient hospital visits, and the Danish National Health Services Prescription Database, which includes data on dispensings from outpatient pharmacies ${ }^{10}$. The IMS RWE LPD panels include EMRs from routine clinical practice from a subset of GPs (GP panel) and pulmonologist (Pulmonologist panel) in France. The study period started on the date of olodaterol launch in each country and ended on the latest date the data were available at the time of each final data extraction. The study periods included in the final data extraction for each data source were from March 1, 2014, to December 31, 2016, in PHARMO and the Danish population registers and from October 1,2015 , to November 30,2017, in the IMS RWE LPD panels. The time periods vary by data source due to time lag in availability of data to researchers. The study was carried out in accordance with relevant guidelines and regulations. The study protocol was approved by the Institutional Review Board (IRB) and by the scientific and ethic committees required by each database. The need for informed consent was waived by the IRB.

Study population. Patients were included in the study if they fulfilled all the following criteria: (1) received a first prescription/dispensing for single-agent formulations of olodaterol or indacaterol during the study period (new users, with no prescriptions/dispensings ever before) and (2) had at least 12 months of continuous enrolment in the study health care databases preceding the index date, i.e., the date of the first prescription/dispensing for olodaterol or indacaterol. Because the study aimed to assess the use of olodaterol and indacaterol in regular clinical practice, no exclusions regarding age, sex, or comorbidity were defined. However, individuals with missing or implausible (e.g., age over 120 years) values for age or sex were excluded.

On-label, off-label, and potential off-label definitions. Patients were classified in three mutually exclusive groups according to their indication. On-label users were defined as patients aged 18 years or older with a recorded diagnosis of chronic bronchitis, emphysema, or "other COPD" (a recorded diagnosis of COPD without specifying chronic bronchitis or emphysema) at any time before the index date or up to 30 days after the index date. A time window of 30 days after index date was used to allow for a diagnosis to be recorded in the data sources when prescriptions/dispensings may be done by another physician ${ }^{13}$. Because COPD can occur in association with asthma, patients aged 18 years or older with a recorded diagnosis for both COPD and asthma were also considered on-label ${ }^{14-16}$. Off-label users were defined as patients aged 17 years or younger or patients aged 18 years or older with a recorded diagnosis of asthma in the absence of a recorded diagnosis for COPD at any time before or up to 30 days after the index date (see codes used to define COPD and asthma in Supplemental Table 2). Potential off-label users were defined as the remaining patients aged 18 years or older with no diagnosis of COPD and no diagnosis of asthma recorded at any time before or up to 30 days after the index date. An alternative definition of COPD (i.e., probable COPD) was applied to identify patients who likely had true COPD but for whom no recorded diagnosis was found in the available data source. Probable COPD was defined as the subset of potential off-label users that had at least two prescriptions/dispensings for a LABA, long-acting muscarinic antagonist (LAMA), or ICS (or combinations) after the age of 40 years but not before ${ }^{17,18}$. Review of a sample of 100 patient profiles, i.e. EMRs in chronological order, per drug in each data source was performed to confirm the appropriate performance of the algorithm to identify COPD and asthma, that no codes had been missed, and that the appropriate time windows were being used.

Patient characteristics. New users of olodaterol and new users of indacaterol were characterized at the index date according to demographic variables (age and sex), lifestyle characteristics as available in each data source (Supplemental Table 3) (smoking, obesity, and alcohol consumption), respiratory and nonrespiratory comorbidities, comedications, and COPD severity. Covariates were ascertained based on all information available before the index date, except for comedications and COPD severity that were ascertained up to one year before index date.

Severity of COPD was evaluated among new users of olodaterol or of indacaterol who had a recorded diagnosis of COPD and were aged 40 years or older before the index date. Severity of COPD was evaluated only in the Netherlands and in Denmark and was not evaluable in France due to lack of information on hospitalization. In this study, severity of COPD was defined using a modified version of the algorithm developed by Verhamme, et al. ${ }^{19}$ and considering the updated recommendations by the Global Initiative for Chronic Obstructive Lung Disease $(\mathrm{GOLD})^{2}$. Severity of COPD was determined based on information on intermittent versus regular bronchodilator medications use, exacerbations with and without hospitalizations, presence of emphysema, and use of nebulizer and oxygen therapy in the last 12 months prior to the index date (see criteria in Supplemental Table 4). 
Statistical analysis. The main analysis estimated the prevalence of off-label use among new users of olodaterol and indacaterol during the overall study period in each data source. Data describing the medical history and comedications of the study population are presented as counts, percentages, medians, and interquartile ranges, as appropriate. All data sources followed a common protocol and analysis plan. Data extraction, cohort selection, variable manipulation, and analysis were performed using SAS version 9.2 or higher.

Ethical approval. All procedures performed in studies involving human participants were in accordance with the ethical standards of the institutional and/or national research committee and with the 1964 Helsinki declaration and its later amendments or comparable ethical standards. For this type of study, based exclusively on routinely collected data, formal consent is not required.

\section{Results}

The study included 4,158 new users of olodaterol and 9,966 new users of indacaterol (Fig. 1) across the three countries. Among users of olodaterol or indacaterol, the main reason for exclusion was not being a new user.

Demographic and lifestyle characteristics. The median age ranged from 63 years (IMS RWE LPD GP panel) to 71 years (Denmark) in new users of olodaterol and ranged from 63 years (IMS RWE LPD GP panel) to 69 years (Denmark) in new users of indacaterol (Table 1). Overall, the proportion of females and males among new users of olodaterol and indacaterol was close to $50 \%$ in all data sources except in the IMS RWE LPD pulmonologist panel, where $64.6 \%$ of the new users of olodaterol and $66.9 \%$ of the new users of indacaterol were males. In most data sources, a high proportion of patients had no information recorded on lifestyle characteristics. Among patients with recorded information on smoking history, the proportion of those who were current smokers was around 50\% in PHARMO-GP and in the IMS RWE LPD GP panel and was higher in the IMS RWE LPD pulmonologist panel, which reported that $90.7 \%$ of the new users of olodaterol and $72.2 \%$ of the new users of indacaterol were current smokers. There was incomplete recording of obesity in all data sources. In the subset of patients in PHARMO-GP for whom information on obesity was available $(72.8 \%$ of those new users of olodaterol and $64.6 \%$ among new users of indacaterol), the proportion of overweight or obese patients was $66.1 \%$ among new users of olodaterol and was $66.7 \%$ among new users of indacaterol. The proportion of patients with a recorded diagnosis of alcohol-related disorders was below $10 \%$ in all health care databases for both olodaterol and indacaterol new users.

Comorbidities (respiratory-related and nonrespiratory-related) ever before the index date. In general, the proportion of patients with recorded respiratory and nonrespiratory diseases was higher among new users of olodaterol than among new users of indacaterol. Frequent respiratory comorbidities other than COPD were asthma, pneumonia, and other respiratory conditions (Table 2). The most frequent nonrespiratory diseases among new users of olodaterol and indacaterol across data sources were hypertension, ischemic heart disease, other forms of heart disease, arrhythmias, renal disease, diabetes mellitus, and malignancies (Table 2).

Comedications (respiratory-related and nonrespiratory-related) prescribed/dispensed within 1 year before the index date. In general, prescriptions/dispensings for respiratory and nonrespiratory medications in the year before the index date were more frequent among new users of olodaterol than among new users of indacaterol in all data sources (Table 2). The most frequent prescription/dispensing for respiratory medications in the year before the index date among new users of olodaterol and indacaterol was LAMA, followed by systemic glucocorticosteroids, short-acting beta2-agonist (SABA), LABA/ICS, nasal glucocorticosteroids, and LABA. The most frequent prescriptions/dispensings for nonrespiratory medications among new users of olodaterol and indacaterol were, in general, cardiovascular medications, followed by systemic antibacterial, proton pump inhibitors, antithrombotic agents, and drugs for musculoskeletal system.

COPD severity among new users with COPD at the index date. Severity of COPD among new users of olodaterol and indacaterol aged 40 years or older with COPD in PHARMO overall, PHARMO-GP, and in Denmark is presented in Table 3. The proportion of patients aged 40 years or older with severe or very severe COPD was lowest in PHARMO-GP and highest in Denmark, ranging from 41.7\% (PHARMO-GP) to 67.1\% (Denmark) among new users of olodaterol and from 42.5\% (PHARMO-GP) to 53.0\% (PHARMO overall) among new users of indacaterol.

Frequency of off-label use of olodaterol and indacaterol. The proportion of patients with off-label prescription/dispensing ranged from 3.5\% (PHARMO overall) to 12.4\% (IMS RWE LPD GP panel) in new users of olodaterol and ranged from $3.5 \%$ (PHARMO overall) to $11.9 \%$ (IMS RWE LPD GP panel) in new users of indacaterol (Fig. 2 and Supplemental Tables 5 and 6). On-label prescribing/dispensing ranged from 47.8\% (PHARMO overall) to $77.7 \%$ (IMS RWE LPD pulmonologist panel) in new users of olodaterol and from $28.7 \%$ (Denmark) to $70.1 \%$ (IMS RWE LPD pulmonologist panel) in new users of indacaterol. The proportion of new users classified as potential off-label prescription/dispensing ranged from $17.3 \%$ in the IMS RWE LPD pulmonologist panel to $48.6 \%$ in PHARMO overall for olodaterol and $20.5 \%$ in the IMS RWE LPD pulmonologist panel to $66.6 \%$ in Denmark for indacaterol. Among those patients classified as having potential off-label prescription/dispensing, between 33.9\% (IMS RWE LPD GP panel) and 76.3\% (PHARMO overall) of the new users of olodaterol and between 20.3\% (IMS RWE LPD GP panel) and 60.0\% (PHARMO overall) of the new users of indacaterol were classified as having probable COPD. 


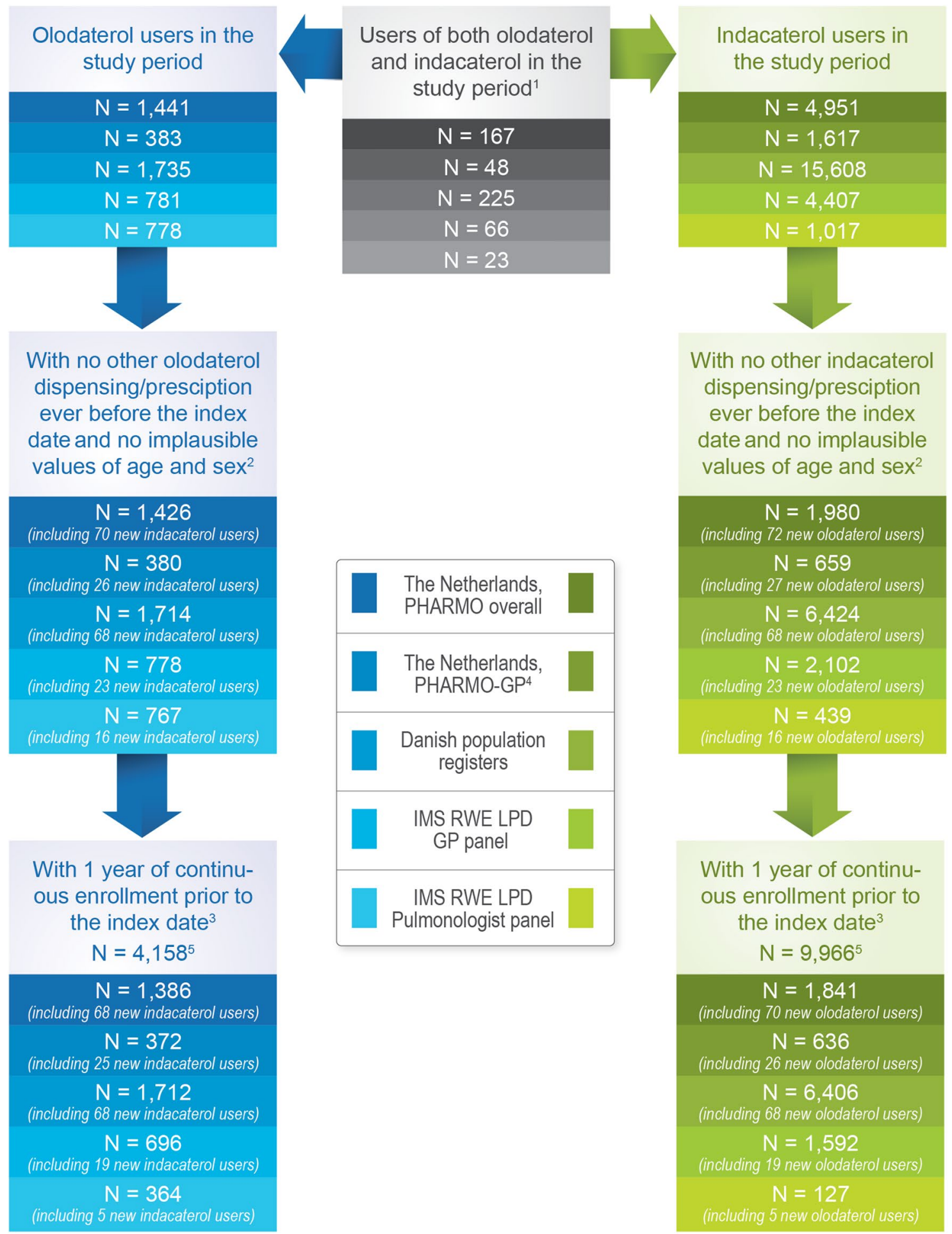

Figure 1. Number of users of olodaterol and indacaterol before and after fulfilling inclusion/exclusion criteria in each data source.

\section{Conclusion}

The prevalence of off-label use of olodaterol (3.5\% to 6.2\%) and indacaterol (3.5\% to $9.4 \%)$ reported in the present study was at the lower bound of the range of off-label use reported by the European Commission (EC) in 2017. In this review, off-label use of different medications, either specific active substances or drug classes, in 13 European studies in a variety of therapeutic areas ranged from $6 \%$ to $72 \%$. Off-label use for respiratory medications indicated either for asthma or COPD was $69 \%$ among patients aged $18-70$ years and $17 \%$ among patients aged $>70$ years $^{20}$. In this study, the prevalence of off-label use of olodaterol and indacaterol was only somewhat higher in 


\begin{tabular}{|c|c|c|c|c|c|c|c|c|c|c|}
\hline & \multicolumn{2}{|c|}{ PHARMO Overall } & \multicolumn{2}{|c|}{ PHARMO-GP } & \multicolumn{2}{|c|}{$\begin{array}{l}\text { Danish population } \\
\text { registers }\end{array}$} & \multicolumn{2}{|c|}{ IMS RWE LPD GP panel } & \multicolumn{2}{|c|}{\begin{tabular}{|l|} 
IMS RWE LPD \\
pulmonologist panel
\end{tabular}} \\
\hline & $\begin{array}{l}\text { Olodaterol } \\
(\mathrm{N}=1,386)\end{array}$ & $\begin{array}{l}\text { Indacaterol } \\
(\mathrm{N}=\mathbf{1 , 8 4 1})\end{array}$ & $\begin{array}{l}\text { Olodaterol } \\
(\mathrm{N}=372)\end{array}$ & $\begin{array}{l}\text { Indacaterol } \\
(\mathrm{N}=636)\end{array}$ & $\begin{array}{l}\text { Olodaterol } \\
(\mathrm{N}=1,712)\end{array}$ & $\begin{array}{l}\text { Indacaterol } \\
(\mathrm{N}=6,406)\end{array}$ & $\begin{array}{l}\text { Olodaterol } \\
(\mathrm{N}=696)\end{array}$ & $\begin{array}{l}\text { Indacaterol } \\
(\mathrm{N}=1,592)\end{array}$ & $\begin{array}{l}\text { Olodaterol } \\
(\mathrm{N}=364)\end{array}$ & $\begin{array}{l}\text { Indacaterol } \\
(\mathrm{N}=127)\end{array}$ \\
\hline Males, $\mathrm{n}(\%)$ & $684(49.4)$ & $954(51.8)$ & $175(47.0)$ & $334(52.5)$ & $735(42.9)$ & $3,082(48.1)$ & $374(53.7)$ & $896(56.3)$ & $235(64.6)$ & $85(66.9)$ \\
\hline Age, median (IQR) & $\begin{array}{l}68.0 \\
(60.0-75.0)\end{array}$ & $\begin{array}{l}68.0 \\
(60.0-75.0)\end{array}$ & \begin{tabular}{|l|}
68.0 \\
$(59.5-$ \\
$76.0)$
\end{tabular} & $\begin{array}{l}68.0 \\
(59.0-74.5)\end{array}$ & $\begin{array}{l}71.0 \\
(64.0-78.5)\end{array}$ & \begin{tabular}{|l}
69.0 \\
$(61.2-76.5)$
\end{tabular} & $\begin{array}{l}63.0 \\
(53.0-72.0)\end{array}$ & $\begin{array}{l}63.0 \\
(53.0-73.0)\end{array}$ & $\begin{array}{l}67.0 \\
(59.0-75.0)\end{array}$ & $\begin{array}{l}67.0 \\
(59.0-75.0)\end{array}$ \\
\hline \multicolumn{11}{|l|}{ Smoking history, n (\%) } \\
\hline Current (or yes) & - & - & $116(31.2)$ & $194(30.5)$ & - & - & $183(26.3)$ & $406(25.5)$ & $136(37.4)$ & $13(10.2)$ \\
\hline Former & - & - & $82(22.0)$ & $108(17.0)$ & - & - & - & - & - & - \\
\hline Never (or no) & - & - & $41(11.0)$ & $64(10.1)$ & - & - & $236(33.9)$ & $496(31.2)$ & $14(3.8)$ & $14(3.8)$ \\
\hline Unknown & - & - & $133(35.8)$ & $270(42.5)$ & - & - & $277(39.8)$ & $690(43.3)$ & $214(58.8)$ & $214(58.8)$ \\
\hline \multicolumn{11}{|c|}{ Obesity or overweight, $\mathbf{n}(\%)$} \\
\hline Yes & $208(15.0)$ & $307(16.7)$ & $179(48.1)$ & $274(43.1)$ & $132(7.7)$ & $385(6.0)$ & $140(20.2)$ & $293(18.4)$ & $79(21.7)$ & $12(9.4)$ \\
\hline No & $93(6.7)$ & $138(7.5)$ & $92(24.7)$ & $137(21.5)$ & NA & NA & $80(11.5)$ & $179(11.2)$ & $44(12.1)$ & $3(2.4)$ \\
\hline Unknown & $1,085(78.3)$ & $1,396(75.8)$ & $101(27.2)$ & $225(35.4)$ & $1,580(92.3)$ & 6,021 (94.0) & 476 (68.4) & $1,120(70.4)$ & $241(66.2)$ & $112(88.2)$ \\
\hline $\begin{array}{l}\text { Alcohol-related } \\
\text { disorders (yes), } \mathbf{n}(\%)^{b}\end{array}$ & $73(5.3)$ & $83(4.5)$ & $17(4.6)$ & $27(4.2)$ & $146(8.5)$ & $600(9.4)$ & $35(5.0)$ & $86(5.4)$ & $0(0.0)$ & $1(0.8)$ \\
\hline
\end{tabular}

Table 1. Description of demographics and lifestyle variables of new users of olodaterol and indacaterol. $\mathrm{GP}=$ general practitioner; IMS RWE LPD = IMS Health Information Solutions Real-World Evidence Longitudinal Patient Database; IQR = interquartile range; $\mathrm{PHARMO}=\mathrm{PHARMO}$ Database Network;

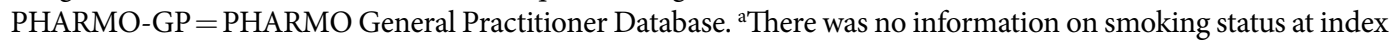

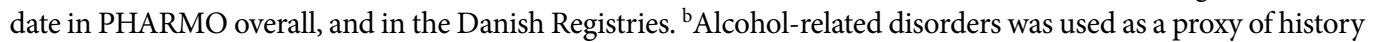
of heavy drinking due to limited availability of data on alcohol consumption at index date in most data sources.

the IMS RWE LPD GP panel (12.4\% for olodaterol and 11.9\% for indacaterol). No notable differences in off-label use were observed between olodaterol and indacaterol.

Results of the present study indicate that new users of olodaterol and indacaterol represent an elderly population, with a similar sex distribution and a high prevalence of respiratory and nonrespiratory comorbidities and use of comedications. In general, age and sex distribution of new users of olodaterol were similar to that of new users of indacaterol, and were in line with findings in former studies ${ }^{19,21-23}$. A high degree of data on lifestyle characteristics were missing due to type and availability of information in the health care databases. New users of olodaterol had more comorbidities and used more comedications than new users of indacaterol. In general, the frequency of comorbidities among new users of olodaterol and indacaterol was in the range of that reported in the literature for patients with COPD, although the prevalence of most nonrespiratory comorbidities such as hypertension or ischemic heart disease was lower than expected in the IMS RWE LPD panels ${ }^{19,22-24}$. Differences in the type and availability of data in each data source and differences in the duration of the look-back period may explain part of the differences observed between data sources. The results indicate that olodaterol, the newer medication, tends to be prescribed to patients who are less stable and need medication changes or to patients with more severe COPD as compared with older medications with similar indications of use (i.e. indacaterol). Differences in the distribution of COPD severity by data source can also be explained by the type and availability of data, i.e., in Denmark only patients who have had a hospital contact for COPD could have a recorded diagnosis of COPD, thus diagnosis of COPD recorded among those patients managed in primary care could not be captured. The proportion of use of other respiratory medications in PHARMO overall, PHARMO-GP, and Denmark was similar to proportions of these medications described in the literature, except that of prior use of ICS, which was lower ${ }^{19,21}$.

The study included a high number of users across different health care systems and data sources in Europe. Performing the study across several data sources increased the number of new users being evaluated and allowed assessment of potential differences in the patterns of use between countries for the medications of interest. Heterogeneity in the type and completeness of the information in these data sources may be driving, at least in part, the differences observed between them. However, the results must be evaluated in the context of the study's two main limitations. First, the data sources used in this study provided detailed information on prescribed/dispensed medications but not on the actual use of the medications, and this may lead to exposure misclassification, which can be worst in patients with COPD, a disease with frequently low adherence and persistence to treatment ${ }^{25,26}$. This type of misclassification is more likely to occur in the IMS RWE LPD panels that have information on prescriptions rather than in the PHARMO and Danish data sources that have information on dispensings ${ }^{27}$. Second, the recorded COPD and asthma diagnosis might be incomplete. In the present study, on-label use was identified only by recorded diagnoses for COPD. It is likely that this method resulted in an underestimation of the prevalence of on-label use due to the potential incomplete recording of COPD diagnosis in the health care data sources [18]. A high proportion of new users of olodaterol and indacaterol had neither recorded COPD nor asthma diagnosis codes and were classified as "potential off-label use". To untangle the potential misclassification due to incomplete recording, a medication algorithm was used to identify patients that were likely to have COPD. A high proportion of up to $76.3 \%$ of the patients in PHARMO overall without a recorded diagnosis of COPD or asthma had "probable COPD" based on the medication proxy, suggesting that these patients are likely using the drug on-label versus what had been identified in the participating health care databases. Results also suggest 


\begin{tabular}{|c|c|c|c|c|c|c|c|c|c|c|}
\hline & \multicolumn{2}{|c|}{ PHARMO Overall } & \multicolumn{2}{|c|}{ PHARMO-GP } & \multicolumn{2}{|c|}{$\begin{array}{l}\text { Danish population } \\
\text { registers }\end{array}$} & \multicolumn{2}{|c|}{ IMS RWE LPD GP panel } & \multicolumn{2}{|c|}{\begin{tabular}{|l|} 
IMS RWE LPD \\
pulmonologist panel
\end{tabular}} \\
\hline & \begin{tabular}{l|} 
Olodaterol \\
$(\mathrm{N}=1,386)$
\end{tabular} & $\begin{array}{l}\text { Indacaterol } \\
(\mathrm{N}=1,841)\end{array}$ & $\begin{array}{l}\text { Olodaterol } \\
(\mathrm{N}=372)\end{array}$ & $\begin{array}{l}\text { Indacaterol } \\
(\mathrm{N}=636)\end{array}$ & $\begin{array}{l}\text { Olodaterol } \\
(\mathrm{N}=1,712)\end{array}$ & $\begin{array}{l}\text { Indacaterol } \\
(\mathrm{N}=6,406)\end{array}$ & $\begin{array}{l}\text { Olodaterol } \\
(\mathrm{N}=696)\end{array}$ & $\begin{array}{l}\text { Indacaterol } \\
(\mathrm{N}=1,592)\end{array}$ & $\begin{array}{l}\text { Olodaterol } \\
(\mathrm{N}=364)\end{array}$ & \begin{tabular}{|l} 
Indacaterol \\
$(\mathrm{N}=127)$
\end{tabular} \\
\hline \multicolumn{11}{|l|}{ Respiratory diseases, $\mathbf{n}(\%)$} \\
\hline COPD & $663(47.8)$ & $653(35.5)$ & $276(74.2)$ & $407(64.0)$ & $1,118(65.3)$ & $1,840(28.7)$ & $374(53.7)$ & $847(53.2)$ & $283(77.7)$ & $89(70.1)$ \\
\hline Asthma & $166(12.0)$ & $202(11.0)$ & $107(28.8)$ & $166(26.1)$ & $261(15.2)$ & $542(8.5)$ & $218(31.3)$ & $457(28.7)$ & $100(27.5)$ & $26(20.5)$ \\
\hline Pneumonia & $210(15.2)$ & $184(10.0)$ & $52(14.0)$ & $87(13.7)$ & $565(33.0)$ & $1,200(18.7)$ & $186(26.7)$ & $319(20.0)$ & $46(12.6)$ & $9(7.1)$ \\
\hline Other respiratory conditions & $191(13.8)$ & $186(10.1)$ & $43(11.6)$ & $60(9.4)$ & $445(26.0)$ & $649(10.1)$ & $60(8.6)$ & $123(7.7)$ & $102(28.0)$ & $19(15.0)$ \\
\hline \multicolumn{11}{|l|}{ Nonrespiratory diseases, $\mathbf{n}(\%)$} \\
\hline Ischemic heart disease & $213(15.4)$ & $258(14.0)$ & $49(13.2)$ & $71(11.2)$ & $405(23.7)$ & $1,236(19.3)$ & $88(12.6)$ & $176(11.1)$ & $28(7.7)$ & $7(5.5)$ \\
\hline Arrhythmias & $171(12.3)$ & $179(9.7)$ & $48(12.9)$ & $78(12.3)$ & $269(15.7)$ & $796(12.4)$ & $84(12.1)$ & $187(11.7)$ & $23(6.3)$ & $5(3.9)$ \\
\hline Heart failure & $87(6.3)$ & $88(4.8)$ & $29(7.8)$ & $37(5.8)$ & $183(10.7)$ & $384(6.0)$ & $20(2.9)$ & $46(2.9)$ & $5(1.4)$ & $0(0.0)$ \\
\hline Hypertension & $261(18.8)$ & $291(15.8)$ & $96(25.8)$ & $157(24.7)$ & $560(32.7)$ & $1,737(27.1)$ & $305(43.8)$ & $682(42.8)$ & $85(23.4)$ & $17(13.4)$ \\
\hline Other forms of heart diseases & $179(12.9)$ & $226(12.3)$ & $68(18.3)$ & $110(17.3)$ & $384(22.4)$ & $1,255(19.6)$ & $224(32.2)$ & $440(27.6)$ & $21(5.8)$ & $3(2.4)$ \\
\hline Cerebrovascular disease & $73(5.3)$ & $113(6.1)$ & $25(6.7)$ & $41(6.4)$ & $226(13.2)$ & $727(11.3)$ & $45(6.5)$ & $94(5.9)$ & $12(3.3)$ & $1(0.8)$ \\
\hline Hyperlipidemia & $95(6.9)$ & $124(6.7)$ & 47 (12.6) & $77(12.1)$ & $235(13.7)$ & $135(7.9)$ & $193(27.7)$ & $455(28.6)$ & $29(8.0)$ & $8(6.3)$ \\
\hline Renal disease & $166(12.0)$ & $187(10.2)$ & $42(11.3)$ & 74 (11.6) & $385(22.5)$ & $193(11.3)$ & $135(19.4)$ & $296(18.6)$ & $9(2.5)$ & $2(1.6)$ \\
\hline Depressive disorders & $27(1.9)$ & $25(1.4)$ & $23(6.2)$ & $23(3.6)$ & $771(12.0)$ & $303(17.7)$ & $185(26.6)$ & $427(26.8)$ & $26(7.1)$ & $4(3.1)$ \\
\hline Diabetes mellitus & $140(10.1)$ & $167(9.1)$ & $42(11.3)$ & $78(12.3)$ & $1,061(16.6)$ & $543(8.5)$ & $109(15.7)$ & $236(14.8)$ & $35(9.6)$ & $10(7.9)$ \\
\hline Malignancy & $179(12.9)$ & $194(10.5)$ & $49(13.2)$ & $77(12.1)$ & $771(12.0)$ & $1,047(16.3)$ & $85(12.2)$ & $179(11.2)$ & $44(12.1)$ & $6(4.7)$ \\
\hline \multicolumn{11}{|l|}{ Respiratory medications, $\mathbf{n}$ (\%) } \\
\hline LABA $^{\mathrm{a}}$ & $382(27.6)$ & $185(10.0)$ & $104(28.0)$ & $61(9.6)$ & $437(25.5)$ & $351(5.5)$ & $97(13.9)$ & $64(4.0)$ & $51(14.0)$ & $5(3.9)$ \\
\hline LABA/ICS & $514(37.1)$ & $519(28.2)$ & $137(36.8)$ & $170(26.7)$ & $687(40.1)$ & $1,177(18.4)$ & $197(28.3)$ & $334(21.0)$ & $68(18.7)$ & $24(18.9)$ \\
\hline LABA/LAMA & $81(5.8)$ & $5(0.3)$ & $21(5.6)$ & $2(0.3)$ & $190(11.1)$ & $58(0.9)$ & $59(8.5)$ & $2(0.1)$ & $46(12.6)$ & $1(0.8)$ \\
\hline LAMA & $1,088(78.5)$ & $1,081(58.7)$ & $275(73.9)$ & $368(57.9)$ & $1,228(71.7)$ & $1,536(24.0)$ & $296(42.5)$ & $282(17.7)$ & $235(64.6)$ & $39(30.7)$ \\
\hline SAMA & $174(12.6)$ & $193(10.5)$ & $32(8.6)$ & $70(11.0)$ & $12(0.7)$ & $19(0.3)$ & $18(2.6)$ & $13(0.8)$ & $72(19.8)$ & $3(2.4)$ \\
\hline SABA & $623(44.9)$ & $643(34.9)$ & $140(37.6)$ & $210(33.0)$ & $991(57.9)$ & $2,482(38.7)$ & $176(25.3)$ & $349(21.9)$ & $119(32.7)$ & $19(15.0)$ \\
\hline SABA/SAMA & $105(7.6)$ & $54(2.9)$ & $25(6.7)$ & $9(1.4)$ & $98(5.7)$ & $95(1.5)$ & $23(3.3)$ & $38(2.4)$ & $20(5.5)$ & $15(11.8)$ \\
\hline ICS & $378(27.3)$ & $334(18.1)$ & $77(20.7)$ & $95(14.9)$ & $302(17.6)$ & $667(10.4)$ & $117(16.8)$ & $206(12.9)$ & $54(14.8)$ & $18(14.2)$ \\
\hline Systemic glucocorticosteroids & $685(49.4)$ & $617(33.5)$ & $149(40.1)$ & $223(35.1)$ & $662(38.7)$ & $1,188(18.5)$ & $287(41.2)$ & $515(32.3)$ & $54(14.8)$ & $13(10.2)$ \\
\hline \multicolumn{11}{|c|}{ Nonrespiratory medications, $\mathbf{n}(\%)$} \\
\hline Cardiovascular medications & $900(64.9)$ & $1,174(63.8)$ & $246(66.1)$ & $396(62.3)$ & $1,245(72.7)$ & $4,288(66.9)$ & $414(59.5)$ & $865(54.3)$ & $11(3.0)$ & $2(1.6)$ \\
\hline Systemic antibacterials & $824(59.5)$ & $928(50.4)$ & $197(53.0)$ & $317(49.8)$ & $1,179(68.9)$ & $3,493(54.5)$ & $467(67.1)$ & $919(57.7)$ & $84(23.1)$ & $18(14.2)$ \\
\hline Proton pump inhibitors & $765(55.2)$ & $927(50.4)$ & $195(52.4)$ & $337(53.0)$ & $610(35.6)$ & $1,859(29.0)$ & $329(47.3)$ & $676(42.5)$ & $21(5.8)$ & $5(3.9)$ \\
\hline Antithrombotic agents & $602(43.4)$ & $761(41.3)$ & $145(39.0)$ & $261(41.0)$ & $710(41.5)$ & $2,225(34.7)$ & $195(28.0)$ & $362(22.7)$ & $2(0.5)$ & $0(0.0)$ \\
\hline Drugs for musculoskeletal system & - & - & - & - & $433(25.3)$ & $1,511(23.6)$ & $219(31.5)$ & $428(26.9)$ & $1(0.3)$ & $0(0.0)$ \\
\hline
\end{tabular}

Table 2. Number and proportion of patients with medical history of respiratory and nonrespiratory diseases, at any time before index date and up to 30 days after and number and proportion of users of respiratory and nonrespiratory comedications within 12 months prior to index date among new users of olodaterol and indacaterol, by data source. GP = general practitioner; ICS = inhaled glucocorticosteroids; IMS RWE LPD = IMS Health Information Solutions Real-World Evidence Longitudinal Patient Database; LABA = inhaled long-acting beta2-agonist; LAMA = long-acting muscarinic antagonist; NA = not available; PHARMO = PHARMO Database Network; PHARMO-GP = PHARMO General Practitioner Database; $\mathrm{SABA}=$ short-acting beta2-agonists; SAMA $=$ short-acting muscarinic antagonists. ${ }^{\text {PPior }}$ use of LABA includes use of indacaterol for those in the olodaterol group but not indacaterol and vice versa. Note: percentages from column totals are displayed.

that recording of COPD is more incomplete in the IMS RWE LPD GP panel, in the PHARMO overall, and in Denmark compared with PHARMO-GP and the IMS RWE LPD pulmonologist panel. Incomplete recording of COPD diagnosis in the IMS RWE LPD GP panel is likely to occur because of the nature of the database, where only day-to-day diagnoses are recorded and there is no incentive to record all of a patient's comorbidities. In PHARMO overall, only $25 \%$ have primary care data, and in Denmark there is no access to primary care data. The diagnosis and treatment of COPD is often managed by GPs outside hospitals, implying that hospital-based diagnoses capture primarily patients with more severe COPD. Therefore, incomplete recording of COPD is expected when only hospital data and not primary care data is available. This issue is supported by literature showing that COPD prevalence in Denmark was estimated to approximately $4.3 \%$ in hospital settings, while it was estimated to be $12 \%$ in primary care settings ${ }^{8,28}$. Even in health care data sources with access to primary care data, recording may be incomplete when recording is not mandatory for the GPs. Incomplete recording is also supported by the 


\begin{tabular}{|c|c|c|c|c|c|c|}
\hline \multirow[b]{2}{*}{ COPD severity categories, $\mathrm{N}(\%)^{\mathrm{a}}$} & \multicolumn{2}{|c|}{ PHARMO Overall } & \multicolumn{2}{|c|}{ PHARMO-GP } & \multicolumn{2}{|c|}{ Danish population registers } \\
\hline & $\begin{array}{l}\text { Olodaterol } \\
(\mathrm{N}=1,386)\end{array}$ & $\begin{array}{l}\text { Indacaterol } \\
(\mathrm{N}=1,841)\end{array}$ & $\begin{array}{l}\text { Olodaterol } \\
(\mathrm{N}=372)\end{array}$ & $\begin{array}{l}\text { Indacaterol } \\
(\mathrm{N}=636)\end{array}$ & $\begin{array}{l}\text { Olodaterol } \\
(\mathrm{N}=1,712)\end{array}$ & $\begin{array}{l}\text { Indacaterol } \\
(\mathrm{N}=6,406)\end{array}$ \\
\hline $\mathrm{N}$ total & 662 & 648 & 276 & 405 & 1,115 & 1,835 \\
\hline Mild $^{\mathrm{b}}$ & $23(3.5)$ & $63(9.7)$ & $17(6.2)$ & $53(13.1)$ & $67(6.0)$ & $390(21.3)$ \\
\hline Moderate $^{\mathrm{c}}$ & $255(38.5)$ & $242(37.3)$ & $144(52.2)$ & $180(44.4)$ & $300(26.9)$ & $503(27.4)$ \\
\hline Severe $^{\mathrm{d}}$ & $264(39.9)$ & $226(34.9)$ & $69(25.0)$ & $94(23.2)$ & $572(51.3)$ & $779(42.5)$ \\
\hline At least one hospitalization for COPD exacerbation in prior year & $192(72.7)$ & $177(78.3)$ & $35(50.7)$ & $55(58.5)$ & $356(62.2)$ & $450(57.8)$ \\
\hline $\begin{array}{l}\text { At least two COPD exacerbations without hospitalization, where } \\
\text { COPD exacerbation is defined by any of the following: }\end{array}$ & $98(37.1)$ & $47(20.8)$ & $28(40.6)$ & $20(21.3)$ & $392(68.5)$ & $490(62.9)$ \\
\hline A diagnosis of COPD exacerbation without hospitalization & $11(11.2)$ & $6(12.8)$ & $11(39.3)$ & $6(30.0)$ & $32(8.2)$ & $40(8.2)$ \\
\hline A course of antibiotics for respiratory tract infections & $75(76.5)$ & $30(63.8)$ & $18(64.3)$ & $10(50.0)$ & $353(90.1)$ & $453(92.4)$ \\
\hline A course of systemic glucocorticosteroids for COPD exacerbation & $84(85.7)$ & $37(78.7)$ & $21(75.0)$ & $14(70.0)$ & $291(74.2)$ & $323(65.9)$ \\
\hline Very severe $^{e}$ & $120(18.1)$ & $117(18.1)$ & $46(16.7)$ & $78(19.3)$ & $176(15.8)$ & $163(8.9)$ \\
\hline Dispensed oxygen therapy in prior year & NA & NA & NA & NA & $32(18.2)$ & $17(10.4)$ \\
\hline Dispensed nebulizer therapy in prior year & $38(31.7)$ & $14(12.0)$ & $6(13.0)$ & $2(2.6)$ & $45(25.6)$ & $16(9.8)$ \\
\hline Diagnosis of emphysema at any time before index date & $83(69.2)$ & $101(86.3)$ & $39(84.8)$ & $73(93.6)$ & $116(65.9)$ & $135(82.8)$ \\
\hline
\end{tabular}

Table 3. COPD severity among new users aged 40 years or older with COPD at the index date, by study medication and by data source. $\mathrm{COPD}=$ chronic obstructive pulmonary disease; LABA = inhaled long-acting beta2-agonist; $\mathrm{NA}=$ not available; $\mathrm{PHARMO}=\mathrm{PHARMO}$ Database Network; PHARMO-GP $=$ PHARMO General Practitioner Database. ${ }^{a}$ Severity categories were mutually exclusive and patients that fulfill criteria for more than one category were classified as being in the most severe category. The proportion of patients in each COPD severity category was calculated over the total number of new users aged 40 years or older with COPD at the index date. For indented subcategories of the COPD severity groups, the proportion of patients was calculated over the number of patients in the non-indented category or subcategory. ${ }^{b}$ Patients were classified in this category when they did not fulfill criteria for very severe, severe, or moderate. 'At least two prescriptions/ dispensings of the same COPD drug class with a maximum interval of 6 months in the 12 months before index

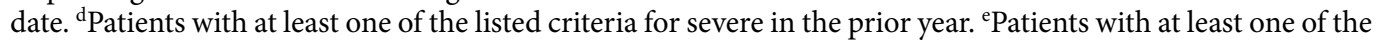
listed criteria for very severe.

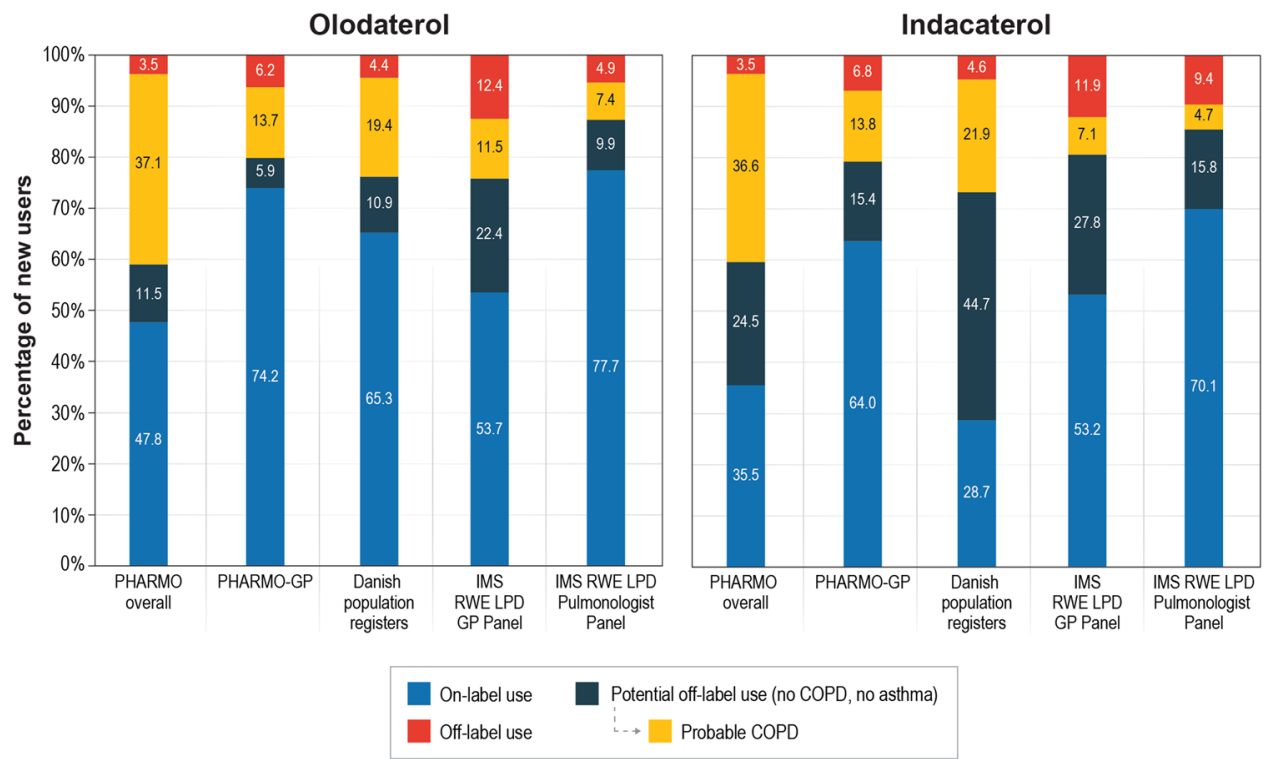

Figure 2. Frequency of off-label, on-label and potential off-label use in new users of olodaterol and indacaterol.

fact that the proportion of patients classified as having "probable COPD" is high in all data sources, but higher in data sources with no primary care data.

Use of olodaterol and indacaterol among patients with asthma only (and no COPD) is expected to be limited to patients who have failed to experience symptom improvement with other LABAs, who may find presentation dosage or device to be less convenient, or who have had drug substance-specific adverse events or contraindications. Routinely collected data used in this study do not specifically record indication for use or patient preference; therefore, the reported level of off-label use is at least partially attributable to the limitations of the data 
sources. Similarly, we cannot completely rule out potential misclassification of COPD as asthma, although it is less likely that true asthma was misclassified as COPD.

Overall, this study provides no evidence of a major concern for an off-label use of olodaterol or indacaterol in asthma or pediatric use of olodaterol or indacaterol in Europe. The lack of direct evidence of prescribed indication (potential off-label use) for a high proportion of patients is a limitation for some data sources, although indirect evidence supports that off-label use is low. Finally, given that asthma management guidelines have consistently and strongly recommended that LABAs should be used only in combination with $\mathrm{ICS}^{13}$, it is expected that use of olodaterol and indacaterol among patients with asthma only is done with concomitant use of ICS, although this was not evaluated in our study.

\section{Data availability}

This study uses the national health care databases, panels of physicians, and registries. Only the aggregated data, in the form of study results in the main manuscript and in the supplementary material can be shared.

Received: 7 August 2019; Accepted: 23 December 2019;

Published online: 17 January 2020

\section{References}

1. Global, regional, and national deaths, prevalence, disability-adjusted life years, and years lived with disability for chronic obstructive pulmonary disease and asthma, 1990-2015: a systematic analysis for the Global Burden of Disease Study 2015. The Lancet. Respiratory medicine 5, 691-706, https://doi.org/10.1016/s2213-2600(17)30293-x (2017).

2. GOLD. Global strategy for the diagnosis, management, and prevention of chronic obstructive pulmonary disease. (Global Initiative for Chronic Obstructive Lung Disease, 2019).

3. Heads of Medicines Agency (HMA). Details: Product Name in the RMS: Striverdi Respimat, http://mri.cts-mrp.eu/Human/ Product/Details/31094 (2013)

4. Chowdhury, B. A. \& Dal Pan, G. The FDA and safe use of long-acting beta-agonists in the treatment of asthma. The New England journal of medicine 362, 1169-1171, https://doi.org/10.1056/NEJMp1002074 (2010).

5. Nelson, H. S., Weiss, S. T., Bleecker, E. R., Yancey, S. W. \& Dorinsky, P. M. The Salmeterol Multicenter Asthma Research Trial: a comparison of usual pharmacotherapy for asthma or usual pharmacotherapy plus salmeterol. Chest 129, 15-26, https://doi. org/10.1378/chest.129.1.15 (2006)

6. Rebordosa, C., Gilsenan, A., Tennis, P. \& Castellsague, J. Drug Utilisation Study for Olodaterol - 03 Aug 2016 - (Version 3.0) (2016).

7. Herings R, P. L. Pharmacy-based Medical Record Linkage Systems. Pharmacoepidemiology. 5 ed edn, 270-286 (2012).

8. Kornum, J. B., Svaerke, C., Thomsen, R. W., Lange, P. \& Sorensen, H. T. Chronic obstructive pulmonary disease and cancer risk: a Danish nationwide cohort study. Respiratory medicine 106, 845-852, https://doi.org/10.1016/j.rmed.2011.12.009 (2012).

9. Schmidt, M. et al. The Danish National Patient Registry: a review of content, data quality, and research potential. Clinical epidemiology 7, 449-490, https://doi.org/10.2147/clep.s91125 (2015).

10. Johannesdottir, S. A. et al. Existing data sources for clinical epidemiology: The Danish National Database of Reimbursed Prescriptions. Clin Epidemiol 4, 303-313, https://doi.org/10.2147/CLEP.S37587 (2012).

11. Schmidt, M., Pedersen, L. \& Sorensen, H. T. The Danish Civil Registration System as a tool in epidemiology. European journal of epidemiology 29, 541-549, https://doi.org/10.1007/s10654-014-9930-3 (2014).

12. Jouaville, S. L., Miotti, H., Coffin, G., Sarfati, B. \& Meihoc, A. Validity And Limitations Of The Longitudinal Patient Database France For Use In Pharmacoepidemiological And Pharmacoeconomics Studies. Value in Health 18, A18, https://doi.org/10.1016/j. jval.2015.03.115 (2015).

13. GINA. Global initiative for asthma (2018).

14. Marsh, S. E. et al. Proportional classifications of COPD phenotypes. Thorax 63, 761-767, https://doi.org/10.1136/thx.2007.089193 (2008).

15. Soriano, J. B., Maier, W. C., Visick, G. \& Pride, N. B. Validation of general practitioner-diagnosed COPD in the UK General Practice Research Database. European journal of epidemiology 17, 1075-1080 (2001).

16. Soriano, J. B., Visick, G. T., Muellerova, H., Payvandi, N. \& Hansell, A. L. Patterns of comorbidities in newly diagnosed COPD and asthma in primary care. Chest 128, 2099-2107, https://doi.org/10.1378/chest.128.4.2099 (2005).

17. Breekveldt-Postma, N. S., Koerselman, J., Erkens, J. A., Lammers, J. W. \& Herings, R. M. Enhanced persistence with tiotropium compared with other respiratory drugs in COPD. Respir Med 101, 1398-1405, https://doi.org/10.1016/j.rmed.2007.01.025 (2007).

18. Overbeek, J. A., Bakker, M. \& Snoeijer, B. T. Abstract 104: The Difference Between Asthma and COPD - A Distinction Based on Dispensing Data. Pharmacoepidimeology and Drug Safety 26, 3-636, https://doi.org/10.1002/pds.4275 (2017).

19. Verhamme, K. M. et al. Tiotropium Handihaler and the risk of cardio- or cerebrovascular events and mortality in patients with COPD. Pulmonary pharmacology \& therapeutics 25, 19-26, https://doi.org/10.1016/j.pupt.2011.10.004 (2012).

20. Weda, M. et al. Study on off-label use of medicinal products in the European Union. February 2017 (2017).

21. de Luise, C., Lanes, S. F., Jacobsen, J., Pedersen, L. \& Sorensen, H. T. Cardiovascular and respiratory hospitalizations and mortality among users of tiotropium in Denmark. European journal of epidemiology 22, 267-272, https://doi.org/10.1007/s10654-007-9106-5 (2007).

22. Laforest, L. et al. Frequency of comorbidities in chronic obstructive pulmonary disease, and impact on all-cause mortality: A population-based cohort study. Respiratory medicine 117, 33-39, https://doi.org/10.1016/j.rmed.2016.05.019 (2016).

23. Schmidt, S. A. et al. The impact of exacerbation frequency on mortality following acute exacerbations of COPD: a registry-based cohort study. BMJ open 4, e006720, https://doi.org/10.1136/bmjopen-2014-006720 (2014).

24. Perez, T., Serrier, P., Pribil, C. \& Mahdad, A. COPD and quality of life: impact of the disease in primary care in France. Revue des maladies respiratoires 30, 22-32, https://doi.org/10.1016/j.rmr.2012.08.005 (2013).

25. Covvey, J. R. et al. A comparison of medication adherence/persistence for asthma and chronic obstructive pulmonary disease in the United Kingdom. International journal of clinical practice 68, 1200-1208, https://doi.org/10.1111/ijcp.12451 (2014).

26. Ingebrigtsen, T. S. et al. Medically treated exacerbations in COPD by GOLD 1-4: A valid, robust, and seemingly low-biased definition. Respiratory medicine 109, 1562-1568, https://doi.org/10.1016/j.rmed.2015.10.015 (2015).

27. Pottegard, A. et al. Primary non-adherence in general practice: a Danish register study. European journal of clinical pharmacology 70, 757-763, https://doi.org/10.1007/s00228-014-1677-y (2014).

28. Hansen, J. G. et al. The Prevalence of chronic obstructive pulmonary disease among Danes aged 45-84 years: population-based study. Copd 5, 347-352, https://doi.org/10.1080/15412550802522635 (2008). 


\section{Acknowledgements}

Joan Forns for medical writing support and Whitney Krueger, forme rly of RTI-HS, and Carla Franzoni, currently of RTI-HS, for project management support. The authors would also like to thank Patricia Tennis, retired from RTI-HS, for her contribution t o the study design and Fernie Penning-van Beest for quality control during the study in PHARMO, as well as all the health care providers contributing information to the PHARMO Database Network. Lisbeth Munksgård Baggesen and Dora Farkas for data analyses of the Danish National Registers. Geoffray Bizouard for data analyses of IMS RWE LPD database. This study was funded by Boehringer Ingelheim $\mathrm{GmbH}$ under a contract granting independent publication rights to the research team. Boehringer Ingelheim co-authors of this manuscript, Ulrich Bothner, Jukka Montonen and Laura Wallace, provided feedback and contributed to the design of the study. The sponsor had the opportunity to review the report and contribute to the dissemination of the results.

\section{Author contributions}

C.R., E.H., K.L., J.A.G., J.O., V.E., J.A.S. \& A.G. provided substantial contributions to study design and interpretation of the data, performed the research, and wrote or critically reviewed the work for important intellectual content. J.A.G., E.H. and J.A.S. also analyzed the data. J.M., U.B. \& L.W. provided substantial contributions to study designed and interpretation of the data and critically reviewed the work for important intellectual content. All authors approved the final version of the manuscript and are accountable for all aspects of this research.

\section{Competing interests}

Cristina Rebordosa, Jaume Aguado, and Alicia Gilsenan are employees of RTI Health Solutions, a unit of RTI International, a non-profit organization that conducts work for government, public, and private organizations, including pharmaceutical companies like Boehringer Ingelheim. Eline Houben and Jetty Overbeek are employees of the PHARMO Institute for Drug Outcomes Research. This independent research institute performs financially supported studies for government and related health care authorities and several pharmaceutical companies. Joelle Asmar is employee of IQVIA, an independent research institute that performs financially supported studies for health care authorities and several pharmaceutical companies. Vera Ehrenstein and Kristina Laugesen are salaried employees of Aarhus University/Aarhus University Hospital. Ulrich Bothner, Jukka Montonen and Laura Wallace are employees of Boehringer Ingelheim.

\section{Additional information}

Supplementary information is available for this paper at https://doi.org/10.1038/s41598-019-57397-5.

Correspondence and requests for materials should be addressed to C.R.

Reprints and permissions information is available at www.nature.com/reprints.

Publisher's note Springer Nature remains neutral with regard to jurisdictional claims in published maps and institutional affiliations.

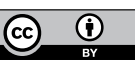

Open Access This article is licensed under a Creative Commons Attribution 4.0 International License, which permits use, sharing, adaptation, distribution and reproduction in any medium or format, as long as you give appropriate credit to the original author(s) and the source, provide a link to the Creative Commons license, and indicate if changes were made. The images or other third party material in this article are included in the article's Creative Commons license, unless indicated otherwise in a credit line to the material. If material is not included in the article's Creative Commons license and your intended use is not permitted by statutory regulation or exceeds the permitted use, you will need to obtain permission directly from the copyright holder. To view a copy of this license, visit http://creativecommons.org/licenses/by/4.0/.

(c) The Author(s) 2020 